\title{
The development of mouthwashes without anti-gonococcal activity for controlled clinical trials: an in vitro study [version
}

\section{1; peer review: 2 approved]}

\author{
Christophe Van Dijck (D1), Vicky Cuylaerts (D1), Piet Sollie (D)2, Anna Spychala2, \\ Irith De Baetselier ${ }^{1}$, Jolein Gyonne Elise Laumen (D1, Tania Crucitti (D), \\ Chris Kenyon ${ }^{1,3}$ \\ ${ }^{1}$ Department of Clinical Sciences, Institute of Tropical Medicine, Antwerp, Antwerp, 2000, Belgium \\ ${ }^{2}$ Pharmacy Sollie, Antwerp, 2000, Belgium \\ 3 University of Cape Town, Cape Town, South Africa
}

V1 First published: 11 Sep 2019, 8:1620

https://doi.org/10.12688/f1000research.20399.1

Latest published: 17 Feb 2020, 8:1620

https://doi.org/10.12688/f1000research.20399.2

\section{Abstract}

Background: The oropharynx plays a major role in the development and spread of antimicrobial resistant Neisseria gonorrhoeae among men who have sex with men. Trials are currently assessing the efficacy of bactericidal mouthwashes as possible therapeutic or preventive options against these pharyngeal gonococcal infections. Controlled clinical trials require the use of a placebo mouthwash without anti-gonococcal activity. So far, no such mouthwash has been described. We describe the development of a mouthwash for this purpose.

Methods: The in vitro anti-gonococcal activity of Corsodyl $\mid \AA$, Listerine Cool Mint ${ }^{\circledR}$, Biotene ${ }^{\circledR}$, phosphate buffered saline and six in-house placebo mouthwashes was evaluated. Three gonococcal isolates from patients with pharyngeal infection were exposed to the mouthwashes for a duration ranging from 30 seconds to 60 minutes. Isolates were then plated onto blood agar ( $5 \%$ horse blood) and incubated for 24 hours $\left(5-7 \% \mathrm{CO}_{2}, 35 \pm 2^{\circ} \mathrm{C}\right)$. Growth of $N$. gonorrhoeae was scored on a five-point scale (0 to 4). All experiments were conducted in duplicate. Results: Corsodyl $₫$ and Listerine Cool Mint $\circledast$ were bactericidal to all isolates. For the other mouthwashes, the median growth score after 60 minutes of exposure was 4 (interquartile range 4-4) for phosphate buffered saline; 1 (interquartile range 1-3) for Biotene ${ }^{\circledR}$; and ranged between 0 and 2 for the in-house composed mouthwashes. An inhouse composed mouthwash (Placebo 6) performed best, with a growth score of 2 (interquartile range 2-3).

Conclusions: All of the evaluated potential placebo mouthwashes were bacteriostatic after gonococcal exposure of 30 to 60 minutes. Inhouse composed Placebo 6 showed less inhibition on gonococcal

\section{Open Peer Review \\ Approval Status \\ 1 \\ 2 \\ version 2 \\ (revision) \\ 17 Feb 2020 \\ version 1 \\ 11 Sep 2019

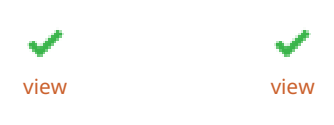 \\ 1. Maarten Franciscus Schim van der Loeff \\ (iD) Public Health Service Amsterdam, \\ Amsterdam, The Netherlands \\ 2. Victoria Miari ID, London School of Hygiene \\ \& Tropical Medicine, London, UK}

Any reports and responses or comments on the article can be found at the end of the article. 
growth than Biotene ${ }^{\circledR}$ and the other in-house placebos and demonstrates, in our opinion, a good trade-off between antigonococcal properties and taste.

\section{Keywords}

Neisseria gonorrhoeae, gonorrhea, pharyngitis, gargle, treatment, eradication, sexually transmitted diseases, placebo, randomized clinical trial, mouthwash

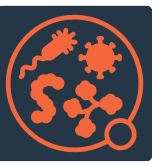

This article is included in the Pathogens gateway.

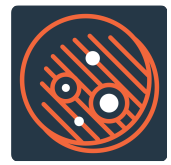

This article is included in the Antimicrobial Resistance collection.

Corresponding authors: Christophe Van Dijck (cvandijck@itg.be), Chris Kenyon (ckenyon@itg.be)

Author roles: Van Dijck C: Formal Analysis, Visualization, Writing - Original Draft Preparation, Writing - Review \& Editing; Cuylaerts V: Investigation, Methodology, Writing - Original Draft Preparation, Writing - Review \& Editing; Sollie P: Conceptualization, Investigation, Writing - Review \& Editing; Spychala A: Conceptualization, Investigation, Writing - Review \& Editing; De Baetselier I: Conceptualization, Data Curation, Funding Acquisition, Methodology, Project Administration, Resources, Supervision, Validation, Writing - Original Draft Preparation, Writing - Review \& Editing; Elise Laumen JG: Writing - Review \& Editing; Crucitti T: Conceptualization, Funding Acquisition, Methodology, Writing - Review \& Editing; Kenyon C: Conceptualization, Data Curation, Formal Analysis, Funding Acquisition, Investigation, Methodology, Project Administration, Resources, Supervision, Visualization, Writing - Original Draft Preparation, Writing Review \& Editing

Competing interests: No competing interests were disclosed.

Grant information: This work was supported by Fonds Wetenschappelijk Onderzoek [FWO 121.00].

The funders had no role in study design, data collection and analysis, decision to publish, or preparation of the manuscript.

Copyright: $\odot 2019$ Van Dijck C et al. This is an open access article distributed under the terms of the Creative Commons Attribution License, which permits unrestricted use, distribution, and reproduction in any medium, provided the original work is properly cited.

How to cite this article: Van Dijck C, Cuylaerts V, Sollie P et al. The development of mouthwashes without anti-gonococcal activity for controlled clinical trials: an in vitro study [version 1; peer review: 2 approved] F1000Research 2019, 8:1620

https://doi.org/10.12688/f1000research.20399.1

First published: 11 Sep 2019, 8:1620 https://doi.org/10.12688/f1000research.20399.1 


\section{Introduction}

The importance of antimicrobial resistance (AMR) in Neisseria gonorrhoeae cannot be overstated. The bacterium is renowned for its capability to acquire AMR and has developed resistance to all classes of antimicrobials used for its treatment ${ }^{1}$. AMR frequently emerges in core groups, such as men who have sex with men (MSM) ${ }^{2}$. The pharmaecological theory of AMR states that a combination of a densely interconnected sexual network and excessive antimicrobial use is an important driver of this resistance ${ }^{3-5}$. If this theory is correct, current efforts to reduce sexually transmitted infection (STI) prevalence via expanded screening and antimicrobial therapy in MSM may paradoxically be playing an important role in the promotion of gonococcal $\mathrm{AMR}^{5,6}$.

These considerations have led to efforts to reduce the prevalence of gonococci in MSM and other core groups with non-antimicrobial products. One option is the use of an antiseptic mouthwash to decrease the oropharyngeal prevalence of gonococci (and other STIs). A modeling study showed that regular use of a mouthwash by MSM could reduce the prevalence of gonococci at different body sites ${ }^{7}$. A further consideration is that the oropharynx plays a central role in the emergence and spread of gonococcal AMR among MSM because of multiple reasons, which are reviewed elsewhere ${ }^{8}$. If a mouthwash can reduce the prevalence of oropharyngeal gonorrhoea without selecting for AMR, this may have the added benefit of reducing the probability of AMR emerging at this site $^{4}$. Two randomized controlled trials (RCTs) are currently underway to assess whether regular mouth washing and gargling in MSM is able to reduce the cumulative incidence of gonorrhoea and other STIs. The OMEGA (Oral Mouthwash use to Eradicate GonorrhoeA) study is an RCT that assesses whether daily use of Listerine Zero $^{\circledR}$ can reduce the incidence of pharyngeal gonorrhoea in a population of Australian MSM (ACTRN12616000247471) ${ }^{9}$. We are conducting a second RCT to assess if the use of Listerine Cool $\mathrm{Mint}^{\circledR}$ (LCM) is able to reduce the cumulative incidence of gonorrhoea (PReGo - Preventing Resistance in Gonorrhoea Study; registered at ClinicalTrials.gov with the identifier NCT03881007).

The choice of an optimal placebo is critical to the success of these RCTs. It is particularly important that a placebo is inert and has no bactericidal or bacteriostatic effect on gonococci. If it did, it would increase the probability of a false negative study outcome.
So far, no study has assessed mouthwashes for this purpose. In this paper, we describe the process of developing and testing a series of candidate placebo mouthwashes. Our aim was to find the most suitable formulation for use as a placebo in the PReGo study. The major criterion we used to assess the mouthwash was its anti-gonococcal activity.

\section{Methods}

Isolates

We used three stored isolates of Neisseria gonorrhoeae that had been previously isolated from the oropharynx of three treatment-naive women with pharyngeal infection at the STI clinic of the Institute of Tropical Medicine, Antwerp, as part of routine gonococcal surveillance monitoring. The isolates were preserved in skimmed milk and $20 \%$ glycerol at $-80^{\circ} \mathrm{C}$ until the experiments were performed. Antimicrobial susceptibility was determined by the agar dilution method according to Clinical \& Laboratory Standards Institute ${ }^{10}$.

\section{Mouthwashes}

The commercially available products Listerine Cool Mint ${ }^{\circledR}$ (LCM, containing alcohol and essential oils) and Corsody ${ }^{\circledR}$ (containing chlorhexidine $0.2 \%$ ) were used to assess the isolate's susceptibility to antibacterial mouthwashes.

Biotene $^{\circledR}$, a commercially available mouthwash that does not contain alcohol, essential oils or chlorhexidine, was expected to have no antibacterial effect and was thus the first mouthwash to be evaluated as a potential placebo substance.

Subsequently, six other potential placebo mouthwashes were manufactured by a pharmacist (Sollie Pharmacy, Antwerp) based on readily available and inexpensive ingredients that are stable at room temperature. Ingredients added to create a medicinal taste were sorbitol, sodium saccharinate, benzoic acid, ethanol, mint spiritus, raspberry extract and/or elderberry extract; ingredients added as a colorant were malachite green, raspberry extract, elderberry extract or solutio viridis. The composition of the mouthwashes is displayed in Table 1 and Table 2. Based on the properties of these ingredients, no major side effects would be expected to occur.

Phosphate buffered saline (PBS, pH $7.3 \pm 0.2$ ) was used as a negative control (inert product allowing unrestricted gonococcal growth) during every experiment.

Table 1. Ingredients of the commercially available mouthwashes, according to their product insert.

\begin{tabular}{|c|c|}
\hline Biotene $^{\circledR}$ & $\begin{array}{l}\text { purified water, glycerin, xylitol, sorbitol, propylene glycol, poloxamer } 407 \text {, sodium benzoate, hydroxyethyl } \\
\text { cellulose, methylparaben, propylparaben, flavor, sodium phosphate and disodium phosphate }\end{array}$ \\
\hline $\begin{array}{l}\text { Listerine Cool } \\
\text { Mint }^{\circledR}\end{array}$ & $\begin{array}{l}\text { aqua, alcohol } 21.6 \% \text {, sorbitol, poloxamer } 407 \text {, benzoic acid, sodium saccharin, eucalyptol } 0.092 \% \text {, aroma, } \\
\text { methyl salicylate } 0.06 \% \text {, thymol } 0.064 \% \text {, menthol } 0.042 \% \text {, sodium benzoate, flavor, green } 3\end{array}$ \\
\hline Corsodyl $^{\circledR}$ & $\begin{array}{l}\text { chlorhexidine digluconate } 0.2 \% \text {, ethanol, peppermint flavour, polyoxyl hydrogenated castor oil, sorbitol, } \\
\text { cochenille red dye (E 124), purified water }\end{array}$ \\
\hline
\end{tabular}


Table 2. Ingredients of the in-house mouthwashes.

\begin{tabular}{|c|c|c|c|c|c|c|c|c|c|c|}
\hline \multirow[b]{2}{*}{ Mouthwash } & \multicolumn{10}{|l|}{ Ingredients } \\
\hline & Sorbitol (g) & $\begin{array}{l}\text { Sodium } \\
\text { saccharinate } \\
\text { (g) }\end{array}$ & $\begin{array}{l}\text { Benzoic } \\
\text { acid (g) }\end{array}$ & $\begin{array}{l}\text { Ethanol } \\
96 \%(g)\end{array}$ & $\begin{array}{l}\text { Mint } \\
\text { spiritus } \\
\text { (g) }\end{array}$ & $\begin{array}{l}\text { Malachite } \\
\text { green }^{\S}(\mathrm{g})\end{array}$ & $\begin{array}{l}\text { Raspberry } \\
\text { extract (g) }\end{array}$ & $\begin{array}{l}\text { Elderberry } \\
\text { extract (g) }\end{array}$ & $\begin{array}{l}\text { Solutio } \\
\text { viridis } \\
\text { (g) }\end{array}$ & $\begin{array}{l}\text { Aqua } \\
\text { conservans* } \\
\text { (g) }\end{array}$ \\
\hline Placebo 1 & 30.00 & 0.10 & 0.20 & 10.00 & 1.10 & 1.75 & & & & 156.85 \\
\hline Placebo 2 & 30.00 & 0.10 & & & 0.66 & 1.75 & & & & 167.49 \\
\hline Placebo 3 & 30.00 & 0.10 & & & & 1.75 & 1.00 & & & 167.15 \\
\hline Placebo 4 & 30.00 & 0.05 & & & & & 1.00 & & & 168.95 \\
\hline Placebo 5 & 30.00 & 0.05 & & & & & & 2.00 & & 167.95 \\
\hline Placebo 6 & 30.00 & 0.10 & & & & & & & 0.70 & 169.20 \\
\hline
\end{tabular}

$\$ 100 \mathrm{~g}$ Malachite green contains: $0.01 \mathrm{~g}$ malachite green oxalate, $99.99 \mathrm{~g}$ aqua conservans.

$\$ 100 \mathrm{~g}$ Solutio viridis contains: $0.3 \mathrm{~g}$ patent blue (E131), $0.3 \mathrm{~g}$ tartrazine (E102), $0.15 \mathrm{~g}$ sodium benzoic acid, $0.1 \mathrm{~g}$ tartaric acid, $99.15 \mathrm{~g}$ purified water.

* $100 \mathrm{~g}$ Aqua conservans contains: $0.0724 \mathrm{~g}$ methylparahydroxybenzoate, $0.0310 \mathrm{~g}$ propylparahydroxybenzoate, $0.9959 \mathrm{~g}$ propylene glycol, $98.901 \mathrm{~g}$ purified water.

\section{Assessment of antibacterial effect}

Each gonococcal isolate was brought into suspension in $3 \mathrm{~mL}$ $\mathrm{PBS}$ at a 0.5 to $0.8 \mathrm{McF}$ arland turbidity, corresponding to a concentration of $10^{8} \mathrm{CFU} / \mathrm{mL}$. From these suspensions, $100 \mu \mathrm{l}$ was then added to $900 \mu \mathrm{L}$ of each mouthwash, resulting in a concentration of $10^{7} \mathrm{CFU} / \mathrm{mL}$. After 30 seconds, 60 seconds, five minutes, 30 minutes and 60 minutes at ambient temperature $\left(20 \pm 5^{\circ} \mathrm{C}\right), 10 \mu \mathrm{L}$ aliquots were plated onto blood agar $(5 \%$ horse blood) and incubated for 24 hours in a $6 \pm 1 \% \mathrm{CO}_{2}$ environment at $35 \pm 2{ }^{\circ} \mathrm{C}$. Bacterial growth was visually scored on a semi-quantitative five-point scale, as described in Figure 1. Plating was conducted in duplicate for each isolate and all bacterial growth assessments were made by a single observer.

No statistical analysis was performed. This study did not involve any experiments on humans or animals and thus no ethical clearance was required.

\section{Results}

All three isolates were susceptible to ceftriaxone and spectinomycin; isolates B and $\mathrm{C}$ had a slightly increased minimum inhibitory concentration (MIC) for azithromycin and isolate A had a high MIC for ciprofloxacin and cefixime. None of the strains produced penicillinase (Table 3 ).

All isolates were fully susceptible to LCM and Corsodyl ${ }^{\circledR}$; a full bactericidal effect was observed after an exposure of 30 seconds or longer (Table 4$)^{11}$.

Exposure to Biotene ${ }^{\circledR}$ for 30 minutes or longer was found to inhibit gonococcal growth considerably (Table 4).

Placebo 1, an ethanol-containing mouthwash was designed to have a similar color and taste as LCM $^{\circledR}$ but led to almost complete inhibition of gonococcal growth even after a short duration of exposure. Placebo 2 contained no ethanol and a lower amount of mint spiritus. Yet, its bacteriostatic effect was comparable to Biotene ${ }^{\circledR}$. In order to determine if mint spiritus or malachite green were the inhibiting factors, these ingredients were sequentially omitted in Placebo 3 and 4. Raspberry extract was added to both in order to improve the taste, but this resulted in strong inhibition of gonococcal growth in both cases. Placebo 5 contained elderberry extract instead, but substantial gonococcal growth inhibition was seen here, too. Placebo 6 contained another type of colorant (solutio viridis) and showed the least bacteriostatic effect after 30 and 60 minutes of exposure (Table 4). During every experiment, there was full and confluent gonococcal growth after exposure to the negative control substance (PBS) (Table 4).

We noted a slight difference in susceptibility to the mouthwashes between the three tested gonococcal isolates. Isolate A was more susceptible to placebos $1-6$ and Biotene ${ }^{\circledR}$ compared with isolates $\mathrm{B}$ and $\mathrm{C}$. However, all strains showed equivalent susceptibility to LCM and Corsodyl ${ }^{\circledR}$ (Table 5 and Table 6). These differences were not assessed for statistical significance.

\section{Discussion}

The recognition of the oropharynx as a source of gonococcal transmission and the genesis of antimicrobial resistance in groups such as MSM has directed research interest towards novel non-antimicrobial methods to prevent or treat oropharyngeal gonococcal infection. Mouthwashes are one such option. In order to determine the efficacy of an intervention involving the use of a mouthwash, RCTs should be performed, and a non-bactericidal placebo is a prerequisite for these trials.

Commercially available non-alcohol containing mouthwashes (like Biotene ${ }^{\circledR}$ ) are an attractive option, but our experiments suggest that exposure to Biotene ${ }^{\circledR}$ for longer than five minutes may inhibit the growth of gonococci. Mouthwashes are typically used for 60 seconds but the substantivity of its ingredients may result in the antibacterial activity of mouthwashes persisting for over six hours ${ }^{12,13}$. To optimize their STI 


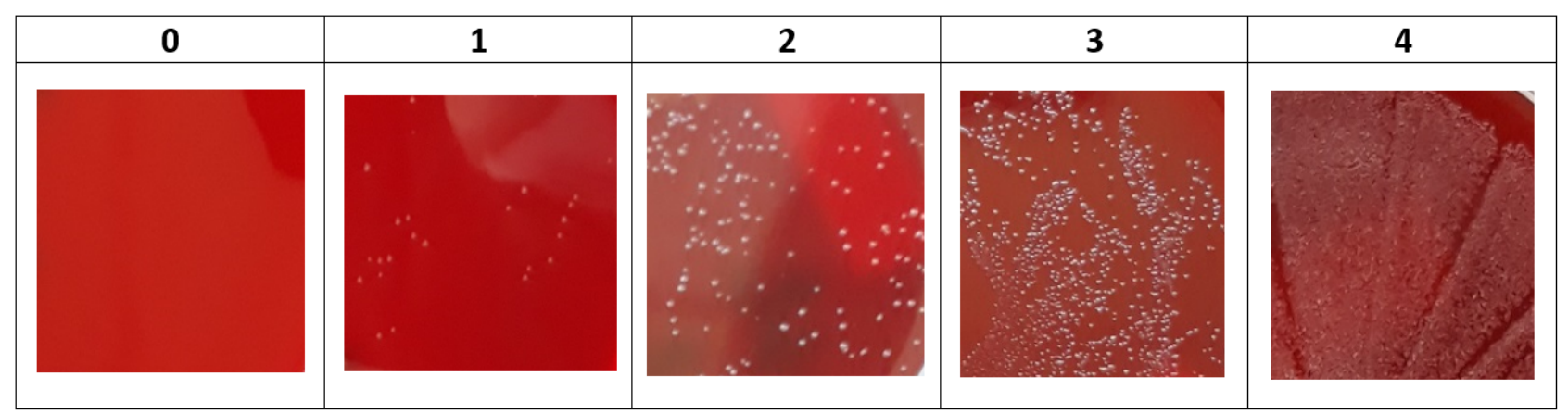

Figure 1. Five-point scale for scoring Neisseria gonorrhoeae growth on blood agar $(0=$ no growth; $1=$ some colonies; 2 = numerous colonies; 3 = entire agar plate covered with colonies; 4 = confluent growth of colonies).

Table 3. Antimicrobial susceptibility of Neisseria gonorrhoeae isolates used in the experiment.

\begin{tabular}{|l|c|c|c|c|c|c|}
\hline & \multicolumn{7}{|c|}{ MIC values (mg/L) } \\
\hline Isolate & Ciprofloxacin & Ceftriaxone & Azithromycin & Spectinomycin & Cefixime & Penicillinase \\
\hline A & 16.000 & 0.030 & 0.250 & 16.000 & 0.250 & negative \\
\hline B & 0.004 & 0.008 & 0.500 & 16.000 & 0.015 & negative \\
\hline C & 0.004 & 0.008 & 0.500 & 16.000 & 0.015 & negative \\
\hline
\end{tabular}

MIC, Minimum Inhibitory Concentration; determined by agar dilution method according to Clinical \& Laboratory Standards Institute.

Table 4. Growth of Neisseria gonorrhoeae after exposure to the mouthwashes.

\begin{tabular}{|l|l|c|c|c|c|c|}
\hline \multirow{2}{*}{ Mouthwash } & N & \multicolumn{5}{|c|}{ Median growth score (IQR) after exposure during } \\
\hline & $\mathbf{3 0}$ seconds & $\mathbf{6 0}$ seconds & $\mathbf{5}$ minutes & $\mathbf{3 0}$ minutes & $\mathbf{6 0}$ minutes \\
\hline Listerine Cool Mint $^{\circledR}$ & 6 & $0(0-0)$ & $0(0-0)$ & NA & NA & NA \\
\hline Corsodyl $^{\circledR}$ & 6 & $0(0-0)$ & $0(0-0)$ & NA & NA & NA \\
\hline Biotene $^{\circledR}$ & 6 & $4(4-4)$ & $4(4-4)$ & $4(2-4)$ & $1(1-3)$ & $1(1-3)$ \\
\hline Placebo 1 & 6 & $1(0-2)$ & $1(0-1)$ & NA & NA & NA \\
\hline Placebo 2 & 6 & $4(4-4)$ & $4(4-4)$ & $3(3-4)$ & $3(1-3)$ & $1(0-2)$ \\
\hline Placebo 3 & 6 & $2(2-2)$ & $0(0-0)$ & $0(0-0)$ & $0(0-0)$ & $0(0-0)$ \\
\hline Placebo 4 & 6 & $2(1-2)$ & $0(0-0)$ & $0(0-0)$ & $0(0-0)$ & $0(0-0)$ \\
\hline Placebo 5 & 6 & $4(4-4)$ & $4(3-4)$ & $3(2-3)$ & $0(0-0)$ & $0(0-0)$ \\
\hline Placebo 6 & 6 & $4(4-4)$ & $4(4-4)$ & $4(3-4)$ & $3(2-4)$ & $2(1-3)$ \\
\hline PBS & 6 & $4(4-4)$ & $4(4-4)$ & $4(4-4)$ & $4(4-4)$ & $4(4-4)$ \\
\hline
\end{tabular}

NA, not assessed; IQR, interquartile range; PBS, phosphate buffered saline.

Table 5. Growth of Neisseria gonorrhoeae after exposure to seven potential placebo mouthwashes (Biotene ${ }^{\circledR}$ and Placebo 1-6).

\begin{tabular}{|l|c|c|c|c|c|c|}
\hline \multirow{2}{*}{ Isolate } & $\mathbf{N}$ & \multicolumn{4}{|c|}{ Median growth score (IQR) after exposure during } \\
\cline { 3 - 7 } & $\mathbf{3 0}$ seconds & $\mathbf{6 0}$ seconds & $\mathbf{5}$ minutes & $\mathbf{3 0}$ minutes & $\mathbf{6 0}$ minutes \\
\hline A & 14 & $3.5(2-4)$ & $3(0-4)$ & $1(0-3)$ & $0.5(0-1)$ & $0(0-1)$ \\
\hline B & 14 & $4(2-4)$ & $4(0-4)$ & $2.5(0-4)$ & $0.5(0-2.5)$ & $0.5(0-1.5)$ \\
\hline C & 14 & $4(1-4)$ & $4(0-4)$ & $3.5(0-4)$ & $1.5(0-3)$ & $0.5(0-3)$ \\
\hline
\end{tabular}

$\mathrm{IQR}$, interquartile range. 
Table 6. Growth of Neisseria gonorrhoeae after exposure to the mouthwashes.

\begin{tabular}{|c|c|c|c|c|c|c|c|}
\hline \multirow{2}{*}{ Isolate } & \multirow{2}{*}{ Mouthwash } & \multirow{2}{*}{$\mathbf{N}$} & \multicolumn{5}{|c|}{ Median growth score (IQR) after exposure during } \\
\hline & & & 30 seconds & 60 seconds & 5 minutes & 30 minutes & 60 minutes \\
\hline \multirow{10}{*}{ A } & Listerine Cool Mint ${ }^{\circledast}$ & 2 & $0(0-0)$ & $0(0-0)$ & NA & NA & NA \\
\hline & Corsody $\left.\right|^{\circledR}$ & 2 & $0(0-0)$ & $0(0-0)$ & NA & NA & NA \\
\hline & Biotene ${ }^{\circledR}$ & 2 & $4(4-4)$ & $4(4-4)$ & $3(3-3)$ & $1(1-1)$ & $1(1-1)$ \\
\hline & Placebo 1 & 2 & $2(2-2)$ & $1(1-1)$ & NA & NA & NA \\
\hline & Placebo 2 & 2 & $4(4-4)$ & $4(4-4)$ & $3(3-3)$ & $1(1-1)$ & $0(0-0)$ \\
\hline & Placebo 3 & 2 & $2(2-2)$ & $0(0-0)$ & $0(0-0)$ & $0(0-0)$ & $0(0-0)$ \\
\hline & Placebo 4 & 2 & $2(2-2)$ & $0(0-0)$ & $0(0-0)$ & $0(0-0)$ & $0(0-0)$ \\
\hline & Placebo 5 & 2 & $4(4-4)$ & $3(3-3)$ & $2(2-2)$ & $0(0-0)$ & $0(0-0)$ \\
\hline & Placebo 6 & 2 & $4(4-4)$ & $4(4-4)$ & $3(3-3)$ & $3(3-3)$ & $2(2-2)$ \\
\hline & PBS & 2 & $4(4-4)$ & $4(4-4)$ & $4(4-4)$ & $4(4-4)$ & $4(4-4)$ \\
\hline \multirow{10}{*}{ B } & Listerine Cool Mint ${ }^{\circledR}$ & 2 & $0(0-0)$ & $0(0-0)$ & NA & NA & NA \\
\hline & Corsody $\left.\right|^{\circledR}$ & 2 & $0.5(0-1)$ & $0(0-0)$ & NA & NA & NA \\
\hline & Biotene $^{\circledR}$ & 2 & $4(4-4)$ & $4(4-4)$ & $2(2-2)$ & $1(1-1)$ & $1(1-1)$ \\
\hline & Placebo 1 & 2 & $0(0-0)$ & $0(0-0)$ & NA & NA & NA \\
\hline & Placebo 2 & 2 & $4(4-4)$ & $4(4-4)$ & $4(4-4)$ & $3(3-3)$ & $2(2-2)$ \\
\hline & Placebo 3 & 2 & $2(2-2)$ & $0(0-0)$ & $0(0-0)$ & $0(0-0)$ & $0(0-0)$ \\
\hline & Placebo 4 & 2 & $2(2-2)$ & $0(0-0)$ & $0(0-0)$ & $0(0-0)$ & $0(0-0)$ \\
\hline & Placebo 5 & 2 & $4(4-4)$ & $4(4-4)$ & $3(3-3)$ & $0(0-0)$ & $0(0-0)$ \\
\hline & Placebo 6 & 2 & $4(4-4)$ & $4(4-4)$ & $4(2-4)$ & $2(2-2)$ & $1(1-1)$ \\
\hline & PBS & 2 & $4(4-4)$ & $4(4-4)$ & $4(4-4)$ & $4(4-4)$ & $4(4-4)$ \\
\hline \multirow{10}{*}{ C } & Listerine Cool Mint ${ }^{\circledR}$ & 2 & $0(0-0)$ & $0(0-0)$ & NA & NA & NA \\
\hline & Corsody $\left.\right|^{\circledR}$ & 2 & $0(0-0)$ & $0(0-0)$ & NA & NA & NA \\
\hline & Biotene $^{\circledR}$ & 2 & $4(4-4)$ & $4(4-4)$ & $4(4-4)$ & $3(3-3)$ & $3(3-3)$ \\
\hline & Placebo 1 & 2 & $1(1-1)$ & $1(1-1)$ & NA & NA & NA \\
\hline & Placebo 2 & 2 & $4(4-4)$ & $4(4-4)$ & $4(4-4)$ & $3(3-3)$ & $1(1-1)$ \\
\hline & Placebo 3 & 2 & $1(1-1)$ & $0(0-0)$ & $0(0-0)$ & $0(0-0)$ & $0(0-0)$ \\
\hline & Placebo 4 & 2 & $2(2-2)$ & $0(0-0)$ & $0(0-0)$ & $0(0-0)$ & $0(0-0)$ \\
\hline & Placebo 5 & 2 & $4(4-4)$ & $4(4-4)$ & $3(3-3)$ & $0(0-0)$ & $0(0-0)$ \\
\hline & Placebo 6 & 2 & $4(4-4)$ & $4(4-4)$ & $4(4-4)$ & $4(4-4)$ & $3(3-3)$ \\
\hline & PBS & 2 & $4(4-4)$ & $4(4-4)$ & $4(4-4)$ & $4(4-4)$ & $4(4-4)$ \\
\hline
\end{tabular}

NA, not assessed; PBS, phosphate buffered saline.

preventive potential, mouthwashes could be used pre and post sex, which could lead to multiple exposures per day. These considerations triggered the search for a placebo with minimal inhibitory effect for periods of up to 60 minutes.

All three isolates in the experiment were fully susceptible to LCM and Corsodyl ${ }^{\circledR}$ and isolate A was most susceptible to all placebo mouthwashes. Although this difference in susceptibility may have been the result of random variability, we could speculate that, in the absence of overt resistance to antiseptics, there might be a mechanism that partially protected isolate B and C from the harmful effect of some of the mouthwash constituents. Isolates $\mathrm{B}$ and $\mathrm{C}$ had a reduced susceptibility to azithromycin. This might have been due to the increased expression of an efflux mechanism such as the Mtr (multiple transferable resistance) efflux pump, which is linked to resistance to macrolides, as well as to many other substances like dyes and detergents ${ }^{14}$. We did, however, not perform genotypic assessment of the isolates used in this experiment.

After testing multiple combinations of ingredients, we found that Placebo 6 had the least bacteriostatic effect in vitro. 
The limitations of this study include the following. First, budget and time constraints did not allow to perform any in vivo evaluation of the mouthwashes. It is of particular interest to know whether participants can distinguish Placebo 6 from an antibacterial mouthwash. A formal head-to-head comparison with LCM is planned as part of the PReGo study. Second, the sample size of the current experiment was too small to statistically assess differences between isolates and between mouthwashes. We may have over- or underestimated the true effect of the mouthwashes. Additionally, the experiments were performed sequentially, which may have introduced some inter-run variation. In each experiment we did however include a PBS exposed control. Third, we did not assess bacterial growth blindly and we did not use a validated quantitative assessment method. Fourth, we used isolates from women with pharyngeal gonococcal infection, which are possibly not representative of the gonococci circulating among MSM. Their susceptibility pattern was, however, similar to that observed in most gonococcal isolates from MSM. Fifth, our in vitro findings are not necessarily representative of the in vivo setting as anatomical and biological properties may influence the effect of a mouthwash against gonococci in the throat. Bioactive molecules in saliva may, for example, have synergistic or antagonistic effects on the mouthwash's active ingredients. Finally, we did not assess the effect of the placebo on the oropharyngeal microbiome. An increased or decreased growth of other oropharyngeal commensals might theoretically compete with gonococcal proliferation in the throat and influence gonococcal infectivity as well.

\section{Conclusion}

This experiment has shown that it is hard to develop an ideal placebo mouthwash as a range of frequently used ingredients inhibit gonococcal growth. A commercially available mouthwash like Biotene ${ }^{\circledR}$ seemed the perfect option at first but it had a bacteriostatic effect. A process of serial testing of various placebos resulted in a placebo mouthwash, which we believe demonstrates a good trade-off between anti-gonococcal properties and taste.

\section{Data availability}

Underlying data

Figshare: In vitro gonococcal growth after exposure to mouthwashes. https://doi.org/10.6084/m9.figshare.9757859 ${ }^{11}$.

This project contains the following underlying data:

- Data.xlsx (spreadsheet containing raw growth scores of the individual isolates after exposure to the experimental substances)

Data are available under the terms of the Creative Commons Zero "No rights reserved" data waiver (CC0 1.0 Public domain dedication)
1. Unemo M, Del Rio C, Shafer WM: Antimicrobial Resistance Expressed by Neisseria gonorrhoeae: A Major Global Public Health Problem in the 21 $1^{\text {st }}$ Century. Microbiol Spectr. 2016; 4(3): 213-37. PubMed Abstract | Publisher Full Text | Free Full Text

2. Lewis DA: The role of core groups in the emergence and dissemination of antimicrobial-resistant $\boldsymbol{N}$ gonorrhoeae. Sex Transm Infect. 2013; 89 Suppl 4: iv47-51.

PubMed Abstract | Publisher Full Text

3. Kenyon C, Osbak K: Certain attributes of the sexual ecosystem of high-risk MSM have resulted in an altered microbiome with an enhanced propensity to generate and transmit antibiotic resistance. Med Hypotheses. 2014; 83(2): 196-202.

PubMed Abstract | Publisher Full Text

4. Kenyon CR, Schwartz IS: Effects of Sexual Network Connectivity and Antimicrobial Drug Use on Antimicrobial Resistance in Neisseria gonorrhoeae. Emerg Infect Dis. 2018; 24(7): 1195-1203.

PubMed Abstract | Publisher Full Text | Free Full Text

5. Kenyon C: Risks of Antimicrobial Resistance in $\mathbf{N}$. gonorrhoeae Associated with Intensive Screening Programs in Pre-Exposure Prophylaxis Programs. Clin Infect Dis. 2018; 67(1): 154-155. PubMed Abstract | Publisher Full Text

6. Kenyon C: We need to consider collateral damage to resistomes when we decide how frequently to screen for chlamydia/gonorrhoea in preexposure prophylaxis cohorts. AIDS. 2019; 33(1): 155-157. PubMed Abstract | Publisher Full Text

7. Zhang L, Regan DG, Chow EPF, et al:: Neisseria gonorrhoeae Transmission among Men Who Have Sex with Men: An Anatomical Site-Specific Mathematical Model Evaluating the Potential Preventive Impact of Mouthwash.
Sex Transm Dis. 2017; 44(10): 586-592.

PubMed Abstract | Publisher Full Text

8. Lewis DA: Will targeting oropharyngeal gonorrhoea delay the further emergence of drug-resistant Neisseria gonorrhoeae strains? Sex Transm Infect 2015; 91(4): 234-7.

PubMed Abstract | Publisher Full Text

9. Chow EPF, Walker S, Hocking JS, et al:: A multicentre double-blind randomised controlled trial evaluating the efficacy of daily use of antibacterial mouthwash against oropharyngeal gonorrhoea among men who have sex with men: the against oropharyngeal gonorrhoea among men who have sex with men: the
OMEGA (Oral Mouthwash use to Eradicate GonorrhoeA) study protocol. BMC OMEGA (Oral Mouthwash
Infect Dis. 2017; 17(1): 456.

PubMed Abstract | Publisher Full Text | Free Full Text

10. CLSI: Methods for Dilution Antimicrobial Susceptibility Tests for Bacteria That Grow Aerobically. 11th ed. CLSI standard M07. Wayne, PA: Clinical and Laboratory Standards Institute. 2018.

11. Van Dijck C: In vitro gonococcal growth after exposure to mouthwashes. 2019 http://www.doi.org/10.6084/m9.figshare.9757859.v1

12. Prada-Lopez I, Quintas V, Donos N, et al.: In situ substantivity of the essential oils in the oral cavity. Microb Pathog Strateg Combat them Sci Technol Educ (A Méndez-Vilas, Ed). 2013; 1112-1122. Reference Source

13. Tomás I, Cousido MC, García-Caballero L, et al:: Substantivity of a single chlorhexidine mouthwash on salivary flora: influence of intrinsic and extrinsic factors. J Dent. 2010; 38(7): 541-6. PubMed Abstract | Publisher Full Text

14. Morse SA, Lysko PG, McFarland L, et al.: Gonococcal strains from homosexual men have outer membranes with reduced permeability to hydrophobic molecules. Infect Immun. 1982; 37(2): 432-8. PubMed Abstract | Free Full Text 


\section{Open Peer Review}

\section{Current Peer Review Status:}

\section{Version 1}

Reviewer Report 04 February 2020

https://doi.org/10.5256/f1000research.22418.r58822

(C) 2020 Miari V. This is an open access peer review report distributed under the terms of the Creative Commons Attribution License, which permits unrestricted use, distribution, and reproduction in any medium, provided the original work is properly cited.

\section{Victoria Miari}

Department of Infectious and Tropical Diseases, London School of Hygiene \& Tropical Medicine, London, UK

\section{Overall}

This study is worthwhile as I'm aware it is difficult to design trials with adequate control solutions.

The study was written well and clearly for the most part; I have included some comments for improvement.

\section{Abstract}

- Please make clear that you are developing a "control" mouthwash rather than an active one.

When you say the experiments were performed in duplicate you suggest that the experiment was performed twice. Reading on, you mention that you performed two measurements from the same experiment which is not an experimental duplicate. Can you rephrase to reflect this? You also mentioned that there is a good trade-off between antigonococcal activity and taste for one placebo; how did you measure this? It is not described in the main study.

\section{Methods}

You mention PBS allows for unrestricted gonococcal growth; I do not believe this is correct; it maintains viability but not growth.

Initial colony counts were not performed; this would have allowed comparison between the different mouthwashes with higher confidence. You cold have also somehow measured reduction in viability; this will need to be justified in the discussion.

You present results for penicillinase; how did you test this. 


\section{Results}

Can you please put title rows on table 1 ?

For Table 2 it would be helpful to mention what the final volume/weight/mass the placebos were, or enter the values as percentages?

Table 6 could perhaps go in supplementary files? The summary tables enough for these results.

\section{Discussion}

What do you mean when you say you did not assess bacterial growth "blindly"? See comments in methods for what else needs to be considered in discussion.

You also mentioned experiments performed sequentially and also plating was performed in duplicate; from the results it seems like one of these was done. Can you clarify this?

Is the work clearly and accurately presented and does it cite the current literature? Yes

Is the study design appropriate and is the work technically sound? Partly

Are sufficient details of methods and analysis provided to allow replication by others? Yes

If applicable, is the statistical analysis and its interpretation appropriate? Not applicable

Are all the source data underlying the results available to ensure full reproducibility? Yes

Are the conclusions drawn adequately supported by the results? Partly

Competing Interests: No competing interests were disclosed.

Reviewer Expertise: Microbiology Laboratory Research

I confirm that I have read this submission and believe that I have an appropriate level of expertise to confirm that it is of an acceptable scientific standard.

Author Response 12 Feb 2020

Christophe Van Dijck, Institute of Tropical Medicine, Antwerp, Antwerp, Belgium We are very thankful to the reviewer for her valuable comments. 
Comment 1: Please make clear that you are developing a "control" mouthwash rather than an active one.

Response: we added the term "placebo" to the abstract and the introduction to make this more clear to the reader.

Comment 2: When you say the experiments were performed in duplicate you suggest that the experiment was performed twice. Reading on, you mention that you performed two measurements from the same experiment which is not an experimental duplicate. Can you rephrase to reflect this? You also mentioned that there is a good trade-off between anti-gonococcal activity and taste for one placebo; how did you measure this? It is not described in the main study.

Response: indeed, only plating was conducted in duplicate. The abstract has been corrected to specify this. Taste was assessed by one of the researchers. We added a sentence to the methods' section to reflect this.

Comment 3: You mention PBS allows for unrestricted gonococcal growth; I do not believe this is correct; it maintains viability but not growth.

Response: indeed, we corrected this in the manuscript.

Comment 4: Initial colony counts were not performed; this would have allowed comparison between the different mouthwashes with higher confidence. You cold have also somehow measured reduction in viability; this will need to be justified in the discussion.

Response: the three isolates used in this experiment were first inoculated onto GC agar. Next, the isolates were brought into 0.5 to $0.8 \mathrm{McF}$ arland $(10 \wedge 8 \mathrm{CFU} / \mathrm{mL})$ suspensions S1. Subsequently, $100 \mu \mathrm{L}$ aliquots of each suspension S1 were then exposed to $900 \mu \mathrm{L}$ of the mouthwashes/PBS, resulting in $10^{\wedge} 7 \mathrm{CFU} / \mathrm{mL}$ suspensions S2. Then $10 \mu \mathrm{L}$ of each suspension S2 were plated onto blood agar. Bacterial growth was assessed $24 \mathrm{~h}$ after inoculation of these $10 \mu \mathrm{L}$ aliquots. As this process was performed in parallel for all the mouthwashes/PBS in this experiment, we feel confident that gonococcal growth could be compared reliably between the mouthwashes. We did, however, not assess residual viability of the surviving bacterial colonies after mouthwash exposure. We added this as a limitation of the study.

Comment 5: You present results for penicillinase; how did you test this. Response: a nitrocefin test was used (Nitrocefin Oxoïd, Thermo Scientific ${ }^{\mathrm{TM}}$ ).

Comment 6: Can you please put title rows on table 1?

Response: ok

Comment 7: For Table 2 it would be helpful to mention what the final volume/weight/mass the placebos were, or enter the values as percentages? Response: ok

Comment 8: Table 6 could perhaps go in supplementary files? The summary tables enough for these results. 
Response: it is F1000R policy to publish all tables within the main manuscript.

Comment 9: What do you mean when you say you did not assess bacterial growth "blindly"? See comments in methods for what else needs to be considered in discussion.

Response: The observer who assessed bacterial growth was not blinded to the ingredients of the mouthwashes. We clarified this in the discussion.

Comment 10: You also mentioned experiments performed sequentially and also plating was performed in duplicate; from the results it seems like one of these was done. Can you clarify this?

Response: Indeed, after testing Biotene ${ }^{\circledR}$, we first tested Placebo 1, then Placebo 2, and so on. In each of these experiments plating of isolates A, B and C was performed in duplicate and a PBS-exposed control was included.

Competing Interests: No competing interests were disclosed.

Reviewer Report 11 November 2019

https://doi.org/10.5256/f1000research.22418.r55772

(C) 2019 Schim van der Loeff M. This is an open access peer review report distributed under the terms of the Creative Commons Attribution License, which permits unrestricted use, distribution, and reproduction in any medium, provided the original work is properly cited.

\section{Maarten Franciscus Schim van der Loeff}

Department of Infectious Diseases, Public Health Service Amsterdam, Amsterdam, The Netherlands

This report by Van Dijck et al. seeks to evaluate the anti-gonococcal activity of several commercially available mouth washes, as well as of one commercial and several in-house produced 'placebo' mouth washes. The authors find that all tested commercially available mouth washes have some anti-gonococcal activity, and that some of the 'placebo' mouth washes did as well.

This study is important as mouth washes have been suggested as a potential tool for prevention of gonorrhoea on an individual and a population level. Trials examining the efficacy of oral mouth wash need a 'placebo' without anti-gonococcal activity. This report provides important data towards that.

This brief report is clearly written. The conclusions are based on the data. The limitations of the small study are clearly described in the Discussion.

I am a physician and epidemiologist and recommend that also a microbiologist should review the manuscript. 
I have a few minor comments:

1. In the abstract it is not clear how the 5-point scale of $N$. gonorrhoeae growth is to be interpreted; make it explicit that 0 means no growth and 4 extensive growth.

2. The abstract mentions an IQR of 2-3 for placebo 6 at 60 minutes; Table 4 mentions an IQR of 1-3. Please check and correct.

3. Not all readers may be familiar with the term "pharmaecological" (perhaps better spelled as "pharma-ecological"?) so a fuller explanation may be helpful.

Is the work clearly and accurately presented and does it cite the current literature? Yes

Is the study design appropriate and is the work technically sound?

Yes

Are sufficient details of methods and analysis provided to allow replication by others? Yes

If applicable, is the statistical analysis and its interpretation appropriate? Yes

Are all the source data underlying the results available to ensure full reproducibility? Yes

Are the conclusions drawn adequately supported by the results?

Yes

Competing Interests: No competing interests were disclosed.

Reviewer Expertise: Infectious diseases, especially sexually transmitted infections; epidemiology

I confirm that I have read this submission and believe that I have an appropriate level of expertise to confirm that it is of an acceptable scientific standard.

\section{Author Response 12 Feb 2020}

Christophe Van Dijck, Institute of Tropical Medicine, Antwerp, Antwerp, Belgium

We are very thankful to the reviewer for his valuable comments.

Comment 1. In the abstract it is not clear how the 5-point scale of $\mathbf{N}$. gonorrhoeae growth is to be interpreted; make it explicit that 0 means no growth and 4 extensive growth.

Response: The abstract has been changed accordingly 
Comment 2. The abstract mentions an IQR of 2-3 for placebo 6 at 60 minutes; Table 4 mentions an IQR of 1-3. Please check and correct.

Response: Thank you for pointing out this error. It has been corrected.

Comment 3. Not all readers may be familiar with the term "pharmaecological" (perhaps better spelled as "pharma-ecological"?) so a fuller explanation may be helpful.

Response: The term pharmaecological has been changed into "pharmaco-ecological" and the sentence has been rephrased to clarify the term.

Competing Interests: No competing interests were disclosed.

The benefits of publishing with F1000Research:

- Your article is published within days, with no editorial bias

- You can publish traditional articles, null/negative results, case reports, data notes and more

- The peer review process is transparent and collaborative

- Your article is indexed in PubMed after passing peer review

- Dedicated customer support at every stage

For pre-submission enquiries, contact research@f1000.com 